\title{
Impulso fiscal e sustentabilidade da dívida pública
}

\author{
Helder Ferreira de Mendonça* \\ Octavio Vargas Freitas Pinton ${ }^{* *}$
}

RESUMO - Este artigo faz uma breve análise da política fiscal brasileira no período 19982007 levando em conta dois indicadores: o impulso fiscal e a sustentabilidade da dívida pública. Devido à complementaridade entre os indicadores, uma análise conjunta de ambos foi realizada. Os resultados indicam uma postura austera do governo brasileiro. Além disso, foi observado que a dívida pública pode não ser sustentável apesar da política fiscal austera.

Palavras-chave: Política fiscal. Sustentabilidade da dívida pública. Impulso fiscal.

\section{INTRODUÇÃO}

As crises financeiras ocorridas na segunda metade dos anos 1990 mudaram a política fiscal brasileira. Esse período marcou o encerramento do ciclo de folga da política fiscal em virtude da escassez de financiamento no mercado externo. Em particular, houve elevado déficit tanto no setor externo quanto no fiscal o que, por conseguinte, implicava a urgente necessidade de rever as diretrizes de política econômica.

Uma das mais importantes mudanças na política fiscal no período pós-Real foi a implementação do Programa de Estabilidade Fiscal e a adoção das metas de superávit primário a partir de $1999 .^{3}$ A introdução de mudanças no regime fiscal teve o objetivo de promover o equilíbrio das contas públicas para permitir a consolidação dos objetivos do Plano Real.

Tomando como referência o período janeiro de 1998 a julho de 2007 este artigo tem por objetivo mostrar se as medidas adotadas pelo governo brasileiro contribuíram para melhorar a situação fiscal.

\footnotetext{
* Doutor em Economia pela UFRJ. Professor Titular do Departamento de Economia da Universidade Federal Fluminense e pesquisador do CNPq. Endereço eletrônico: helderfm@hotmail.com.

** Doutorando em Economia da Universidade Federal Fluminense e Assistente de Pesquisa do IPEA. Endereço eletrônico: octaviopinton@ig.com.br.

3 Sobre o gerenciamento da dívida pública brasileira no período posterior à introdução do Plano Real, ver de Mendonça e Vivian (2008).
} 


\section{INDICADORES DE DISCRICIONARIEDADE E SUSTENTABILIDADE DA POLÍTICA FISCAL}

O indicador de discricionariedade utilizado neste estudo é o "impulso fiscal" (IF). Este indicador representa a mudança discricionária na posição orçamentária do governo (ALESINA; PEROTTI, 1995). Para a construção do IF é preciso calcular as elasticidades da despesa e da receita do governo federal em relação às principais variáveis macroeconômicas. A primeira variável considerada na análise é o PIB, pois ela encontra-se diretamente ligada à receita (por meio da carga tributária) e à despesa (por meio dos investimentos públicos).

Outra variável presente no estudo é a taxa de inflação (medida pelo IPCA) por desempenhar papel fundamental desde a adoção do regime de metas de inflação em junho de 1999. ${ }^{4}$ Também é importante lembrar que o índice de preços é um dos principais indexadores da dívida mobiliária brasileira. Assim, dependendo da sua variação, o governo se esforçará mais ou menos para gerar resultados primários capazes de honrar seus compromissos.

Outras variáveis que também se mostram relevantes para a economia brasileira no período são as taxas de juros (Selic) e de câmbio. A primeira, além de ser o principal instrumento de política monetária é o principal indexador da dívida pública no período em análise. Deve-se notar que uma elevação na Selic provoca uma elevação no custo da dívida pública. Logo, há a necessidade do governo ampliar o superávit primário para cobrir o serviço da dívida, ou seja, o governo deverá adotar uma postura fiscal mais severa.

A utilização do câmbio como variável de ajuste para o cálculo do IF depende de dois pontos. O primeiro depende do nível de liberalização da conta de capitais, enquanto que o segundo depende do regime cambial que vigora no país. ${ }^{5}$ Deve-se ressaltar que o regime de câmbio fixo não apresentou influência significativa na receita/despesa do governo para ser incorporada no modelo como variável de ajuste.

A influência da taxa de câmbio sobre as contas do governo federal ocorre de duas formas. A primeira é que, da mesma forma que a Selic e o IPCA, a taxa de câmbio nominal é um indexador da dívida mobiliária. A segunda é via taxa de câmbio real. Ou seja, uma depreciação do real frente às outras moedas poderia levar a uma melhora no saldo em transações correntes e, por conseguinte, no resultado primário.

A razão dívida/PIB constitui um indicador de solvência da dívida pública de um país.

\footnotetext{
${ }^{4}$ Para uma análise da relação entre a adoção do regime de metas de inflação e suas consequências sobre o lado fiscal, ver de Mendonça e Silva (2009).

5 Para avaliar o impacto do grau de liberalização na economia é utilizado o índice de controle de capitais elaborado por de Mendonça e Pires (2007).
} 
Logo, um forte aumento nessa razão corrói a credibilidade deste país. Destarte, é razoável que quando esta razão aumente o governo se empenhe em obter resultados primários maiores para manter a percepção de solvência da dívida pública por parte dos agentes econômicos.

É esperado que tanto a receita quanto a despesa do governo federal sejam sensíveis às variáveis macroeconômicas supracitadas. Para observar tal relação foram calculadas as correlações das variáveis PIB, IPCA, Selic, câmbio nominal e o câmbio real (variáveis de ajuste) com as variáveis fiscais (receita e despesa do governo federal). O resultado obtido mostra que o PIB é a variável que possui a correlação mais forte, tanto com a receita quanto com a despesa. Porém, a receita possui um índice de correlação maior do que a despesa, ou seja, conforme o PIB aumenta, a receita aumenta mais que despesa. Quanto ao IPCA foi observada uma correlação desprezível. A justificativa para esse resultado se deve ao fato de que o período em estudo é marcado por uma inflação relativamente baixa e estável. ${ }^{6}$

Em relação à correlação da Selic, observa-se que devido ao fato dela ser muito elevada o governo foi forçado a obter resultados primários cada vez maiores para esterilizar a pressão sobre endividamento público. Além disso, a maior correlação para a receita do que para a despesa sugere que quando a Selic decresce a diferença entre a receita e a despesa aumenta gerando superávits primários maiores. O câmbio nominal mostrou uma correlação significativa. Dado que parte da dívida pública é indexada ao câmbio nominal, no caso de haver uma depreciação da moeda, o governo teria de aumentar o esforço fiscal. O câmbio real não apresentou correlação significativa. Por último, a razão dívida/PIB apresentou uma relação positiva tanto com a receita quanto com a despesa.

Além das variáveis serem correlacionadas, as mesmas também devem ser estacionárias. Para tanto, foram executados testes de raiz unitária. Porém, como o período sob análise apresentou algumas turbulências, os testes de raiz unitária foram feitos levando em conta a presença de quebra estrutural. O resultado obtido indica que todas as variáveis utilizadas no modelo são I(1) e que os seus resíduos são estacionários.

O cálculo da elasticidade das variáveis explicativas (câmbio nominal, PIB, Selic, Dívida/PIB e IPCA) em relação às variáveis independentes (receita e despesa) é feito por meio de Mínimos Quadrados Ordinários (MQO), de acordo com a seguinte especificação:

$$
\log R_{t}=\alpha+\beta \log c n_{t}+\phi \log \operatorname{div}_{t}+\varphi \log i p c a_{t}+\gamma \log p i b_{t}+\mu \log \text { selic }_{t}+\varepsilon_{t}
$$

onde $\alpha, \beta, \phi, \varphi, \gamma$ e $\mu$ são as elasticidades.

\footnotetext{
${ }^{6}$ As correlações, assim como os demais testes realizados, estão disponíveis por meio de solicitação direta aos autores.
} 
Para a despesa, as elasticidades são estimadas com a mesma especificação. Os resultados obtidos encontram-se na Tabela 1.

O valor ajustado é obtido da seguinte maneira:

$$
\log \hat{R}_{t}=\hat{\alpha}+\hat{\beta} \log c n_{t-12}+\hat{\phi} \log d i v_{t-12}+\hat{\varphi} \log i p c a_{t-12}+\hat{\gamma} \log p i b_{t-12}+\hat{\mu} \log \text { selic }_{t-12}
$$

TABELA 1 - ESTIMAÇÃO DAS ELASTICIDADES (JANEIRO/1997-JULHO/2007)

\begin{tabular}{|c|c|c|c|c|c|}
\hline & Variáveis & Coeficiente & Desvio Padrão & Estatística-t & Prob. \\
\hline \multirow{7}{*}{ 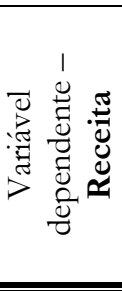 } & Constante & $-4,356$ & 1,157 & $-3,766$ & 0,0003 \\
\hline & Câmbio Nominal & 0,029 & 0,109 & 0,266 & 0,7910 \\
\hline & Dívida/PIB & 0,219 & 0,184 & 1,187 & 0,2374 \\
\hline & IPCA & $-0,039$ & 0,029 & $-1,336$ & 0,1841 \\
\hline & PIB & 1,172 & 0,056 & 21,100 & 0,0000 \\
\hline & Selic & $-0,008$ & 0,047 & $-0,172$ & 0,8638 \\
\hline & $\mathrm{R}^{2}$ ajustado 0,934 & \multicolumn{2}{|r|}{ Schwarz $-1,371$} & \multicolumn{2}{|c|}{ Estat.-F 359,01 } \\
\hline \multirow{8}{*}{ 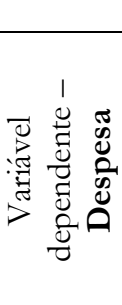 } & Variáveis & Coeficiente & Desvio Padrão & Estatística-t & Prob. \\
\hline & Constante & $-4,689$ & 1,319 & $-3,555$ & 0,0005 \\
\hline & Câmbio Nominal & $-0,053$ & 0,125 & $-0,424$ & 0,6722 \\
\hline & Dívida/PIB & 0,165 & 0,210 & 0,785 & 0,4338 \\
\hline & IPCA & $-0,029$ & 0,033 & $-0,860$ & 0,3915 \\
\hline & PIB & 1,204 & 0,063 & 18,997 & 0,0000 \\
\hline & Selic & 0,030 & 0,053 & 0,557 & 0,5782 \\
\hline & $\mathrm{R}^{2}$ ajustado 0,908 & & Schwarz $-1,108$ & \multicolumn{2}{|c|}{ Estat.-F 249,77 } \\
\hline
\end{tabular}

FONTE: Elaboração própria

Ou seja, a variável $\log \hat{R}_{t}$ representa qual seria o valor da receita do governo no mês $t$ caso as variáveis econômicas não tivessem se alterado. Dessa forma, o valor do IF é calculado como:

$$
I F=\left(\hat{D}_{t}-\hat{R}_{t}\right)-\left(D_{t-12}-R_{t-12}\right)
$$

onde $\hat{D}_{t}$ e $\hat{R}_{t}$ são os valores ajustados do mês $t$, e $D_{t-12}$ e $R_{t-12}$ são os valores observados no mesmo mês do ano anterior $(t-12)$. O IF é encontrado subtraindo o déficit primário ajustado do déficit primário observado do período passado.

Tanto no caso da despesa como da receita, o valor ajustado é ligeiramente inferior ao observado. Ou seja, se não houvesse a influência do ambiente econômico nas contas do governo, este arrecadaria e gastaria menos do que o observado.

A postura do governo é classificada de acordo com intervalos estabelecidos na tabela 2 (ver ALESINA; PEROTTI, 1995). Caso o IF do período se situe entre -5 e 5, a postura é "neutra", se o indicador for maior de 5 a postura é "expansionista". Quando o IF for menor que -5 , o governo está adotando uma postura “austera". Portanto, em 115 meses foram observados 50 meses em que o IF indicou uma postura "neutra", 20 meses com uma postura "austera", 13 meses foram classificados como "muito austera", 15 meses com postura "expansionista" e 17 meses como "muito expansionista". Apesar de certo equilíbrio na 
divisão entre as possibilidades de classificação possíveis, a soma dos indicadores indicou uma postura "muito austera". Neste caso, considerando todo o período, o valor do IF observado é $-27,55$.

Para analisar a sustentabilidade da dívida pública deve-se testar a existência de cointegração entre os fluxos de receitas e gastos do governo. Destarte, foram realizados testes de cointegração baseados em Engle-Granger e Johansen para o período de janeiro de 1997 a julho de 2007. O resultado obtido sugere que a dívida pública é sustentável no período. Para confirmar o resultado foi verificado se a série da dívida é estacionária (ver Rocha, 1997, e Trehan e Walsh, 1988). Assim, foram realizados os testes ADF, PP e KPSS e foi verificado que a série não é $\mathrm{I}(0)$ para os testes $\mathrm{ADF}$ e PP. Logo, há divergência em relação ao resultado apresentado pelos testes de cointegração.

TABELA 2 - CLASSIFICAÇÃO E ESTATÍSTICAS DO IMPULSO FISCAL

\begin{tabular}{l|c|c|c}
\hline \multicolumn{1}{c|}{ Postura } & Classificação & Observações & \% \\
\hline Neutra & Entre -5 e 5 & 50 & 43,5 \\
Expansionista & De 5 a 10 & 15 & 13,0 \\
Austera & de -10 a -5 & 20 & 17,4 \\
Muito Expansionista & maior que 10 & 17 & 14,8 \\
Muito Austera & menor que -10 & 13 & 11,3 \\
\hline Total & & 115 & 100,0 \\
\hline \hline
\end{tabular}

FONTE: Elaboração própria.

\section{ANÁLISE CONJUNTA DOS INDICADORES}

Como o IF foi calculado em periodicidade mensal, quando se agrega o resultado dos meses do ano, obtêm-se a postura do governo daquele ano específico (vide Tabela 3). Na análise por ano, pode-se perceber que o governo brasileiro adotou uma postura austera ao longo do período. Porém, como o indicador mede a postura do ano $t$ em relação ao ano $t-1$, pode-se dizer que quando o resultado mostra uma postura neutra, na verdade, o governo está adotando a mesma postura que a do ano anterior. Há ainda um outro ponto TABELA 3 - CLASSIFICAÇÃO POR ANO

\begin{tabular}{l|c|c}
\hline \hline Ano & Impulso Fiscal & Postura \\
\hline 1998 & $-12,22$ & Muito Austera \\
\hline 1999 & $-17,06$ & Muito Austera \\
\hline 2000 & 13,51 & Muito Expansionista \\
\hline 2001 & $-0,80$ & Neutra \\
\hline 2002 & $-34,53$ & Muito Austera \\
\hline 2003 & $-27,33$ & Muito Austera \\
\hline 2004 & 3,59 & Neutra \\
\hline 2005 & $-0,42$ & Neutra \\
\hline 2006 & 19,50 & Muito Expansionista \\
\hline \hline
\end{tabular}

FONTE: Elaboração Própria 
importante quanto à análise de política fiscal - a influência do ambiente econômico. O IF exclui parte do resultado que não é de controle do formulador de política.

Quando se combinam os dois indicadores é possível avaliar se: (i) a dívida foi sustentável no ano por causa da postura do governo; (ii) a dívida foi sustentável no ano apesar da postura do governo; (iii) a dívida não foi sustentável no ano por causa da postura do governo; e (iv) a dívida não foi sustentável no ano apesar da postura do governo (vide Tabela 4). Assim, observa-se que grande parte da austeridade encontrada nos resultados pode ser explicada pelo esforço fiscal iniciado em 1999 com a adoção das metas de superávit primário pelo governo brasileiro e que foi intensificada em 2002 com a ampliação dessas metas. A austeridade só foi atenuada em 2006.

TABELA 5 - RESULTADOS DOS ANOS

FONTE: Elaboração própria.

\begin{tabular}{l|c|c}
\hline \hline \multicolumn{1}{c|}{ Ano } & Sustentabilidade da Dívida Pública & IF \\
\hline 1999 & sustentável & muito austera \\
\hline 2000 & sustentável & muito expansionista \\
\hline 2001 & sustentável & neutra \\
\hline 2002 & sustentável & muito austera \\
\hline 2003 & sustentável & muito austera \\
\hline 2004 & sustentável & Neutra \\
\hline 2005 & sustentável & Neutra \\
\hline 2006 & não sustentável & muito expansionista \\
\hline \hline
\end{tabular}

Ao longo do primeiro semestre de 2007, a postura adotada pelo governo não foi suficiente para que a dívida voltasse a apresentar um perfil sustentável. Mesmo com arrecadações cada vez maiores, e elevados superávits primários, a postura do governo em 2007, considerando apenas os primeiros seis meses do ano, foi classificada como "muito expansionista" $(I F=28)$. O indicador IF revela que no primeiro semestre dos anos a postura do governo é na maioria das vezes expansionista, enquanto que no segundo semestre, o governo compensa os gastos excessivos ou a baixa receita, e adota uma postura mais austera.

Dada a discrepância entre os semestres, surge uma nova questão: qual é o impacto desta temporalidade fiscal na sustentabilidade da dívida pública? Com o objetivo de responder a esta pergunta foi testada a estacionariedade da dívida a cada semestre. De acordo com os testes realizados constatou-se que apesar da alternância de postura ao longo dos anos, a sustentabilidade da dívida só foi modificada no primeiro semestre de 2006.

De acordo com Alesina e Perotti (1995) uma política fiscal de ajuste (assumida como "austera" ou "muito austera" em $t$ ) é considerada uma política de "sucesso", se em $t+3$ a razão dívida/PIB se reduzir em pelo menos cinco pontos percentuais (p.p.). Fazendo-se uso do mesmo critério, observa-se que para os nove anos em que foi estimado o IF, nenhum ano 
apresentou uma postura "austera", e em apenas três anos a postura foi classificada como "muito austera" (vide tabela 6). Destarte, a política de ajuste implementada em 1999 não pode ser considerada como um "sucesso".

Outra análise pertinente é como esses ajustes foram feitos, isto é, se por aumento da arrecadação (aumento da receita) ou via diminuição dos gastos (diminuição da despesa). Analisando os dados de ambas as variáveis, tanto os valores observados quanto os valores ajustados, percebe-se que em 1999 as variáveis observadas agiram no sentido do ajuste, isto é, houve um aumento acima da média da arrecadação e um aumento abaixo da média dos gastos do governo federal. Entretanto, o aumento da despesa ficou mais distante da média do que o da receita, ou seja, o ajuste da política fiscal considerando os dados observados foi feito principalmente via contensão da despesa. Quando os dados ajustados são analisados, a austeridade foi menos severa, pois a receita ajustada ficou pouco abaixo da média, enquanto que a despesa ficou abaixo da média.

TABELA 6 - SUCESSO DOS AJUSTES DA POLÍTICA FISCAL

\begin{tabular}{l|c|c|c|c}
\hline \hline & Dívida /PIB no ano $\mathbf{t}$ & $\mathbf{t}+\mathbf{1}$ & $\mathbf{t + 2}$ & $\mathbf{t + 3}$ \\
\hline 1999 & $44,5 \%$ & $45,5 \%$ & $48,4 \%$ & $50,5 \%$ \\
\hline 2002 & $50,5 \%$ & $52,4 \%$ & $47,0 \%$ & $46,5 \%$ \\
\hline 2003 & $52,4 \%$ & $47,0 \%$ & $46,5 \%$ & $44,9 \%$ \\
\hline \hline
\end{tabular}

FONTE: Elaboração própria.

Em 2002, a receita observada apresentou um aumento muito acima da média do período 1997-2006, enquanto que o aumento da despesa ficou pouco acima da média. Os dados ajustados da receita indicaram um aumento igual à média do período, enquanto as despesas aumentaram abaixo da média. Logo, de acordo com os dados observados, o ajuste fiscal foi feito pela receita, ao passo que pelos dados ajustados via despesa.

No último ano que apresentou uma postura "muito austera" (2003) tanto o aumento da receita quanto o da despesa observada ficaram abaixo da média, enquanto que os aumentos das variáveis ajustadas ficaram acima da média. Este fato em si, não permite nenhuma conclusão relevante. Porém, quando se analisa a magnitude dos aumentos, nota-se que nos dados observados a diferença da despesa em relação a sua média é mais acentuada do que na receita, isto é, o ajuste fiscal ocorreu mais pela despesa do que pela receita. Realizando a mesma análise para os dados ajustados, percebe-se que a superioridade da receita em relação à média é maior que a da despesa o que, por conseguinte, permite a mesma conclusão. 


\section{CONCLUSÃO}

O resultado anual do IF revelou uma postura significativamente austera entre 1998 e 2006. Os anos em que a postura apresentou característica mais austera foram 1998 (início do processo de ajuste fiscal) e os anos em que ocorreram as crises mais graves (1999, 2002 e 2003). A austeridade também foi confirmada quando se considera a influência dos ciclos econômicos.

Os testes aplicados, tanto de discricionariedade da política fiscal e o de sustentabilidade da dívida apontaram para uma dívida pública não sustentável, embora a política fiscal tenha sido extremamente austera. Este resultado se deve ao elevado custo da dívida pública interna brasileira. Apesar dos elevados superávits primários apresentados, estes não foram suficientes para pagar o serviço da dívida. Dessa forma, o montante da dívida pública em todo o período apresentou uma trajetória crescente. Em suma, o esforço do governo foi mais no sentido de melhorar a composição da dívida do que em diminuí-la.

Para aprofundar a análise acerca dos ajustes fiscais, se conjeturou sobre a forma que eles foram feitos, se via aumento da arrecadação ou por meio da diminuição dos gastos. A análise foi feita tanto pelos dados observados, quanto pelos dados ajustados (quando se exclui a influência do ambiente macroeconômico). Constatou-se que em 1999 e 2003 os ajustes fiscais foram realizados via despesa, enquanto que em 2002 via receita. Quanto à análise dos dados ajustados, constatou-se que em 1999 e 2002 os ajustes fiscais foram realizados via despesa, enquanto que em 2003 pela receita.

Os resultados supracitados, quando conjugados à análise de sucesso dos ajustes mostrou-se relevante. Nos anos em que o ajuste fiscal foi feito via diminuição dos gastos não houve sucesso na redução da razão dívida/PIB em cinco p.p.. Porém, quando o ajuste foi realizado via aumento da arrecadação o governo conseguiu fazer com que a razão dívida/PIB decrescesse o necessário para a obtenção do "sucesso". 


\section{REFERÊNCIAS}

ALESINA, A.; PEROTTI, R. "Fiscal Expansions and Fiscal Adjustments in OECD Countries", NBER Working Papers series, N. 5214, agosto, 1995.

de MENDONÇA, H. F.; PIRES, M. C. C.. "Capital Account Liberalization and Inflation: Evidence from Brazil”. Applied Economics Letters, V. 14, 483-487, 2007.

de MENDONÇA, H.F.; SILVA, R.T. "Fiscal effect from inflation targeting: the Brazilian experience.” Applied Economics, 41(7), 885-897, 2009.

de MENDONÇA, H.F.; VIVIAN, V.S. "Public-debt management: the Brazilian experience." CEPAL Review, 94, 145-162, 2008.

ROCHA, F. "Long-Run Limits on the Brazilian Governmente Debt". Revista Brasileira de Economia, V. 51, N. 4, 447-470, 1997.

TREHAN, B.; WALSH, C. "Common Trends, the Government Budget Constraint, and Revenue Smoothing.” Journal of Economic Dynamics and Control, V.12, 425-444, 1988. 
